\title{
EFFECT OF SUPERCRITICAL CARBON DIOXIDE ON DYEABILITY AND PHYSICAL PROPERTIES OF ULTRA-HIGH-MOLECULAR-WEIGHT POLYETHYLENE FIBER
}

\author{
Jaehyuk Ma1, Tarek Abou Elmaaty², Satoko Okubayashi ${ }^{1}$ \\ ${ }^{1}$ Department of Advanced Fibro-Science, Kyoto Institute of Technology, Matsugasaki, Sakyo-ku, Kyoto 606-8585, Japan, \\ Tel.: +81 75724 7367, Fax: +81 757247337 \\ ${ }^{2}$ Department of Textile Dyeing \& Finishing, Faculty of Applied Art, Damietta University, Damietta 34512, Egypt, Tel. and Fax: +20 572353098 \\ Corresponding author e-mail: okubay@kit.ac.jp
}

\begin{abstract}
:
Supercritical carbon dioxide dyeing, a new type of anhydrous dyeing method, has a lot of advantages, mainly conservation of energy, prevention of pollution, reusability of dye, and many more. This study presents a viable method for the dyeing of an ultra-high-molecular-weight polyethylene (UHMWPE) fabric by using supercritical carbon dioxide $\left(\mathrm{scCO}_{2}\right)$ as a medium. Five hydrozono propanenitrile dyes that are functional colorants having antibacterial activity were applied for the dyeing of the UHMWPE fabric in $\mathrm{scCO}_{2}$ at a pressure of $20 \mathrm{MPa}$ and at temperature of $120^{\circ} \mathrm{C}$. The dyeability of UHMWPE fabric under $\mathrm{ScCO}_{2}$ was evaluated by color measurement, whereby the color strength K/S was calculated. As the treating time and concentration of dye increased, the dyeability of the UHMWPE fabric displayed the tendency to continually improve. As decaline was added into $\mathrm{scCO}_{2}$ as the cosolvent, we obtained higher K/S. Furthermore, color fastness to rubbing and sublimation of the dyed UHMWPE fabric were determined according to Japanese Industrial Standards (JIS) L 08492 and JIS L 0854, and the trend showed that the increase in fastness corresponded to the increase in duration of the treatment. The influence of scCO dyeing on the mechanical properties of UHMWPE was also examined. Consequently, it was found that dyeing in $\mathrm{ScCO}_{2}$ containing decaline reduced the crystallinity of the UHMWPE fabric and the breaking strength decreased. The antimicrobial property of UHMWPE dyed with N'-(2-chloro-4-methylphenyl)-2-oxo-2-(p-tolyl)acetohydrazonoyl cyanide was tested against three different microorganisms, and the results have been reported.
\end{abstract}

\section{Keywords:}

supercritical carbon dioxide dyeing, hydrozono propanenitrile dye, decaline, crystallinity, tensile strength, antibacterial activity

\section{Introduction}

Supercritical fluid dyeing (SFD) is an alternative process to dye hydrophobic synthetic fibers [1-4]. For SFD processes, carbon dioxide is commonly applied as a medium due to its beneficial characteristics, such as nontoxicity, low price, recyclable nature, and easy access to the critical conditions at $T \mathrm{C}=304.34 \mathrm{~K}$ and $\mathrm{PC}=7.38 \mathrm{MPa}$ [5]. $\mathrm{CO}_{2}-$ beyond its critical point - has low viscosity, high diffusivity [6], high density, high solubility, and so on. Recently, modern tools such as ultraviolet (UV) radiation, microwave radiation, and plasma treatment are being applied to improve the dyeability of fiber by etching the fiber surface before the dyeing process [7-11]. However, supercritical carbon dioxide $\left(\mathrm{scCO}_{2}\right)$ has inert behavior toward organic compounds, so it does not damage the materials. One of the most important reasons for using $\mathrm{scCO}_{2}$ is that the dyeing process does not require the use of water, unlike the other conventional dyeing processes. Carbon dioxide in its supercritical state takes on a role similar to that of water (being a solvent) in an aqueous dye. This dyeing method has many benefits such as conservation of energy, prevention of pollution, reusability of dye, and so on [12-14]. Polyester (polyethylene terephthalate [PET]) [1519] and nylon fibers $[20,21]$ were successfully dyed using the $\mathrm{scCO}_{2}$ process. In previous works, we also reported on the SFD of polyester and Nylon-6 fabrics with newly synthesized dyes with antibacterial activities [22, 23]. Polypropylene (PP) fiber, which is generally colored by adding pigment in a spinning dope, was also dyed under $\mathrm{scCO}_{2}$ medium and is expected to be commercialized for sportswear [24].

Ultra-high-molecular-weight polyethylene (UHMWPE) fiber is also one of the materials that are hard to be dyed in aqueous media such as PP. Only carbon and hydrogen compose the polymer by simply repeating, so its chemical structure is quite elemental. The fiber has low density, high degree of crystallinity (DC), and has high draw ratio when produced by gel spinning. Therefore, it displays extreme physical properties such as high strength and high modulus $[25,26]$, which make UHMWPE fiber important for applications in the industrial field such as manufacture of protective equipment, rope, fishing nets, and so on. Despite having such beneficial properties, due to its high crystallinity, a dense molecular structure and lack of functional groups, it is difficult for the fiber to interact with many substances, including conventional dyestuff. Therefore, many researchers have been studying various methods to dye the UHMWPE fiber [27-29].

In this paper, the SFD technique has been employed to color UHMWPE fabric. The hydrozono propanenitrile dyes with 
antimicrobial property were prepared and used for the SFD of UHMWPE. We investigated the influence of addition of decaline in $\mathrm{scCO}_{2}$ as a cosolvent on the dyeability of UHMWPE by measuring the color uptake, expressed as the color strength $K / S$. Decaline and paraffin oil have been successfully used for gel spinning of UHMWPE [30-33]; so decaline is expected to adsorb onto UHMWPE, inducing fiber swelling and decreasing the crystallinity, which could promote dye diffusion in UHMWPE fiber during $\mathrm{scCO}_{2}$ dyeing. The effects of treatment in $\mathrm{scCO}_{2}$ containing decaline on the mechanical properties of UHMWPE were also examined. Furthermore, color fastness to rubbing and sublimation, as well as the antibacterial activities against three microbial cultures, was also tested and the results are discussed.

\section{Experimental}

\subsection{Materials}

The UHMWPE plane woven fabric $\left(160 \mathrm{~g} / \mathrm{m}^{2}\right)$ used in this study was IZANAS $^{\circledR}$ (SK60 1320dtex), kindly supplied by Toyobo Co., Ltd., Otsu, Japan, and it was used for dyeing without any pretreatment. All dyes used in this study were synthesized in our laboratory according to the method described in literature [34] and used for dyeing experiments. The dyes were prepared by mixing a solution of ß-oxoalkanenitriles in ethanol; then, the mixture was solidified with sodium acetate solution to form the aryl diazonium salts. The solid products formed were collected by filtration and recrystallization. The International Union of Pure and Applied Chemistry (IUPAC) names and chemical structures are given in Figure 1. Decaline, with a purity of $95 \%$, was purchased from Nacalai Tesque, Inc., Kyoto, Japan, and used without further purification.

\subsection{Apparatus}

Figure 2 shows a diagram of an apparatus for $\mathrm{scCO}_{2}$ dyeing. The liquefied $\mathrm{CO}_{2}$ departing from a cylinder moved inward to the cooling unit, an externally closed cooling water circulator (CF300, Yamato Scientific Co., Ltd.) and was infused into an intelligent pump (PU-2086, Jasco Corporation). High-pressure $\mathrm{CO}_{2}$ ultimately flowed into a dyeing vessel (EV-2; Jasco Corporation). A dyeing vessel with volume of $50 \mathrm{~mL}$, an oven with magnetic stirrer (SCF-Sro; Jasco Corporation) was used in the $\mathrm{ScCO}_{2}$ dyeing in batch method.
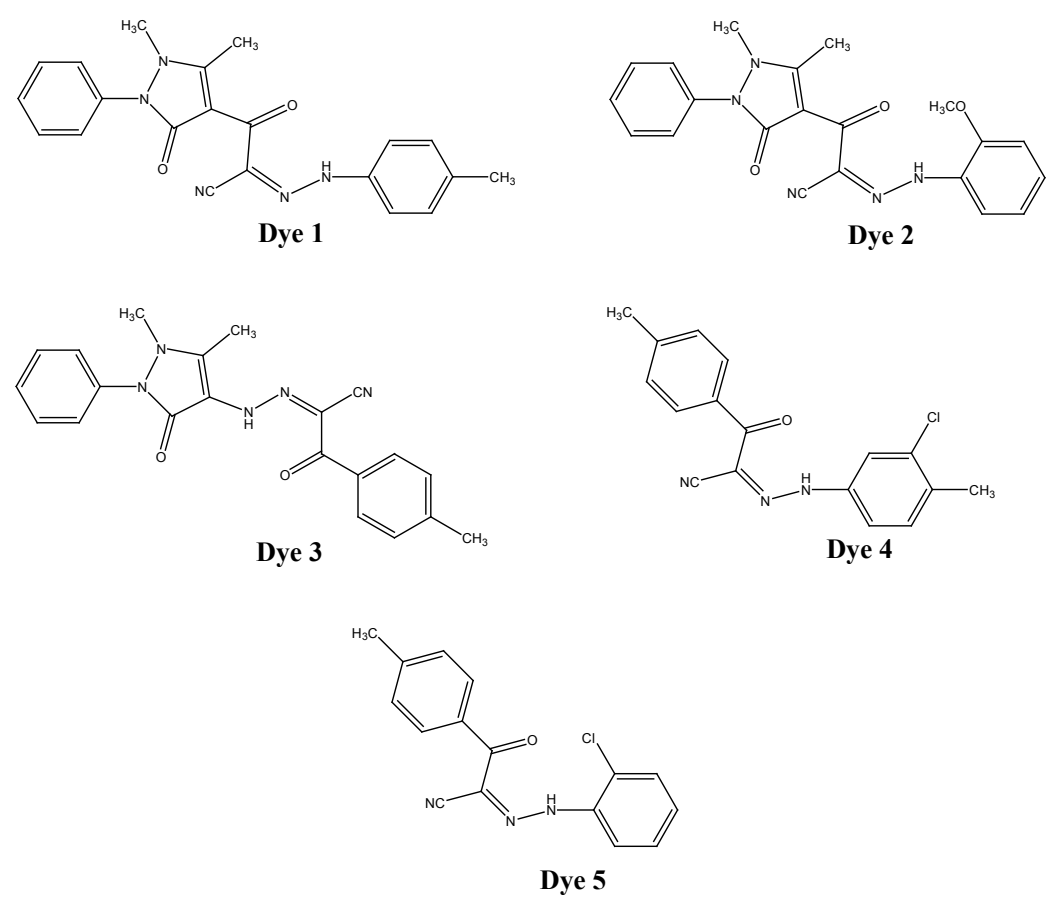

\section{Code}

Name (IUPAC)

Dye 1: 2-(1,5-dimethyl-3-oxo-2-phenyl-2,3-dihydro-1H-pyrazol-4-yl)-2-oxo-N'-(p-tolyl) acetohydrazonylcyanide

Dye 2:

2-(1,5-dimethyl-3-oxo020phenyl-2,3-dihydro-1H-pyrazol-4-yl)-N'-(2methoxyphenyl)-2-oxoacetohydrazonoyl cyanide

Dye 3:

2-([1,1'-biphenyl]-4-yl-N'-(1,5-dimethyle-3-oxo-2-phenyl-2,3-dihydro-1H-pyrazol-4-yl)-2-oxoacetohydrazonoyl cyanide

Dye 4:

N'-(2-chloro-4-methylphenyl)-2-oxo-2-(p-tolyl) acetohydrazonoyl cyanide

Dye 5: N'-(2-chlorophenyl)-2-oxo-2-(p-tolyl) acetohydrazonoyl cyanide

Figure 1. Chemical structure and IUPAC names of the dyes 


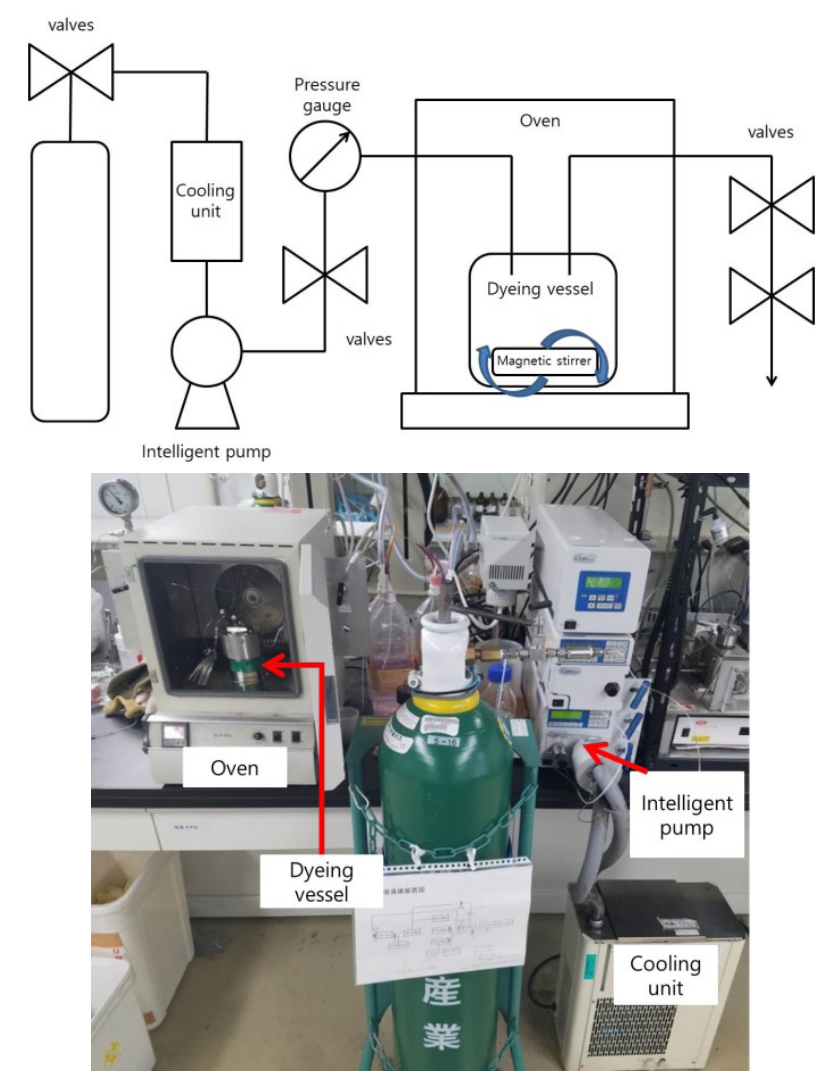

Figure 2. An apparatus for supercritical $\mathrm{CO}_{2}$ dyeing

\subsection{Procedures}

The UHMWPE fabric $(5 \mathrm{~cm} \times 5 \mathrm{~cm})$ was folded and put in a coil of stainless wire (SUS316) to prevent direct contact with dyestuff, and the coil was seated inside the vessel. The dye varying from $2 \%$ over mass of fabric (omf) to $6 \%$ omf was loaded in the bottom of the vessel, and $7 \mathrm{~mol} \%$ of the cosolvent decaline was added in the bottom of the vessel. The amount of decaline was decided according to a previous study [34] and recalculated in mole percent ( $\mathrm{mol} \%$ ), which is the ratio of moles of decaline to the total moles of $\mathrm{CO}_{2}$ and decaline at $120^{\circ} \mathrm{C}$ and $20 \mathrm{MPa}$.

The vessel was then sealed and heated to $120^{\circ} \mathrm{C}$. Then, $\mathrm{CO}_{2}$ was pumped into the vessel and kept at $20 \mathrm{MPa}$ with stirring. After a definite reaction time, the $\mathrm{CO}_{2}$ was released by opening the valve slowly until the pressure of the dyeing vessel reached atmospheric pressure. The vessel was detached from the oven and cooled down at room temperature for 20 minutes. The dyed sample was taken out from the vessel and rinsed with $50 \mathrm{~mL}$ water for 1 minute or cold acetone for 10 seconds to remove unadsorbed dye on the fiber surface.

\subsection{Measurements}

Color uptake expressed as the color strength, $K / S$, of the dyed UHMWPE fabrics and was calculated using the KubelkaMunk equation [Eq. (1)], with reflectance $R$ measured using a spectrophotometer (CM-3600d; Konica Minolta, Inc.).

$$
K / S=(1-R)^{2} /(2 R)
$$

where $K$ is the absorption coefficient and $S$ is the scattering coefficient.
Color fastness to rubbing and sublimation of the dyed UHMWPE fabric was determined according to Japanese Industrial Standards (JIS) L 08492 and JIS L 0854, corresponding to International Organization for Standardization (ISO) 105-X12 and ISO 105-A01, respectively. The rubbing test was carried out with dry samples only. Under the rubbing test, the fabric was placed on the finger of the crock meter and moved back and forth across the dyed UHMWPE fabrics at a constant speed 100 times. The specimen for the sublimation test was inserted between polyester fabrics, and it was subjected to $12.5 \mathrm{kPa}$ and $120^{\circ} \mathrm{C}$ condition for 80 minutes. The results of these evaluations were given by five grades, from 1.0 for the lowest to 5.0 for the highest, and the results were determined by examination with the naked eye.

Differential scanning calorimetry (DSC) was performed on a TA Instruments DSC 2920 under $\mathrm{N}_{2}$ flow at a heating rate of $10^{\circ} \mathrm{C} / \mathrm{min}$. The fibers were cut into $4-5 \mathrm{~mm}$ pieces, placed in an aluminum pan, and closed with an aluminum lid. The DSC measurement was carried out with an empty aluminum pan. The sample weight was approximately $4 \mathrm{mg}$. The DC was calculated from Eq. (2) using the heat of fusion obtained by the following relation:

$$
\text { Degree of crystallinity, } \Delta \mathrm{C}(\%)=\Delta \mathrm{H} / \Delta \mathrm{H}_{\mathrm{m}}
$$

where $\Delta \mathrm{H}$ is the heat of fusion of the sample and $\Delta \mathrm{H}_{\mathrm{m}}$ is heat of fusion of a perfect crystal of PE, viz., $286.7 \mathrm{~mJ} / \mathrm{mg}$ [35].

The UHMWPE woven fabric slipped and slid during tensile measurement even when adhesive agents and tapes were used. To decrease sliding of the specimen, the test was carried out for a multifilament specimen consisting of 10 monofilaments visually counted and extracted from each UHMWPE fabric at $25^{\circ} \mathrm{C}$ and at a cross-head speed of $10 \mathrm{~mm} / \mathrm{min}$ using the testing machine AGS-J (Shimadzu Co.). For each fabric's sample, 20 multifilament specimens were tested, and the maximal breaking stress was recorded. The cross-sectional area of the multifilament sample was estimated from the diameter of the monofilament, measured using a scanning electron microscope. Then, the average of the maximal breaking strength and the modulus were calculated.

Assessment of antibacterial activity against Gram+ve bacteria (Staphylococcus aureus and Bacillus subtilis) and Gramve bacteria (Escherichia coli) was conducted according to quantitative assessment by percentage reduction test (American Association of Textile Chemists and Colorists [AATCC] 100-2004).

Specimens of UHMWPE dyed in supercritical medium were shaken in a known concentration of bacterial suspension and the reduction in bacterial activity in the standard time was measured. The efficiency of the antimicrobial treatment was determined by comparing the reduction in bacterial concentration of the treated sample with that of control sample, expressed as a percentage reduction in the standard time.

$$
\text { Reduction }(\%)=[(A-B) / B] \times 100
$$


where $A$ and $B$ are the surviving cells (colony forming unit $[\mathrm{cfu}] / \mathrm{mL}$ ) in the flasks containing the control and test samples, respectively, after 24 hours of contact time.

\section{Results and discussion}

\subsection{Dyeing conditions and color strength}

Figure 3 shows the relations between the color strength $K / S$ of the UHMWPE fabric dyed with $2 \%$ omf of dye in $\mathrm{scCO}_{2}$ and the dyeing time at a temperature of $120^{\circ} \mathrm{C}$ and a pressure of $20 \mathrm{MPa}$ [36].

Except for Dye 1, the dye uptake - expressed as color strength $(K / S)$ - was enhanced with increase in the dyeing time up to 3 hours, though the K/S values for Dye 1, Dye 2, and Dye 3 were small. The results may be attributed to the low affinity of the abovementioned three dyes containing a polar pyrazole moiety and/or their larger molecules to the UHMWPE fiber, as compared with Dye 4 and Dye 5 . Since Dye 4 provided the highest $K / S$, additional experiments were carried out with only Dye 4.

The effect of decaline on the dyeing of the UHMWPE fabric in $\mathrm{scCO}_{2}$ was examined. Decaline is generally used for the spinning of UHMWPE [30, 31]. Therefore, we expected improvement of its dyeability by swelling the fibers. The results are given in Figure $4[37,38]$. The aqueous dyeing was carried out with $6 \%$ omf Dye 4 at $120^{\circ} \mathrm{C}$ and at a liquor ratio of $1: 20$. The K/S of the samples dyed in $\mathrm{scCO}_{2}$ was much higher than that for samples dyed in water, and it increased on adding decaline, especially for long dyeing durations. As expected, the fiber could gradually swell in the presence of decaline, which induces the rapid and easy diffusion of dye molecules and further dye adsorption on the fiber surface.

Figure 5 shows the influence of concentration of Dye 4 on the dye uptake, expressed as the color strength $K / S$ of the UHMWPE fiber dyed in decaline/scCO $[39,40]$. For short dyeing, mainly, 1 hour, and at lower dye concentrations, mainly, $2 \%$ omf and $4 \%$ omf, there was no significant effect of dye concentration on $K / S$. On the other hand, the $K / S$ increased with dyeing time up to 3 hours, and no saturation point was found in the range of experimental conditions. The results suggested that specific time periods and concentrations were required for the dye to be adsorbed onto the fiber and to start diffusing into it. Unusually, the difference in $K / S$ between $4 \%$ omf and $6 \%$ omf is much larger than the difference between $4 \%$ omf and $2 \%$ omf at any dyeing time. This may be due to plasticization lowering the crystallinity caused by adsorption of larger amount of dyestuff. The details are discussed in Section 3.2, "Dyeing conditions and physical properties". The dyeing results were quite different from those for the widely used synthetic fibers, e.g., PET and polyamide (Nylon) with conventional disperse dyes, where K/S is in the range of $12-21$ for PET fibers and dyeing starts saturating in 1 or 2 hours [41-44]. This fact maybe due to the high crystallinity and low affinity of UHMWPE to the dye. Further experiments are needed to clarify the dyeing mechanism.

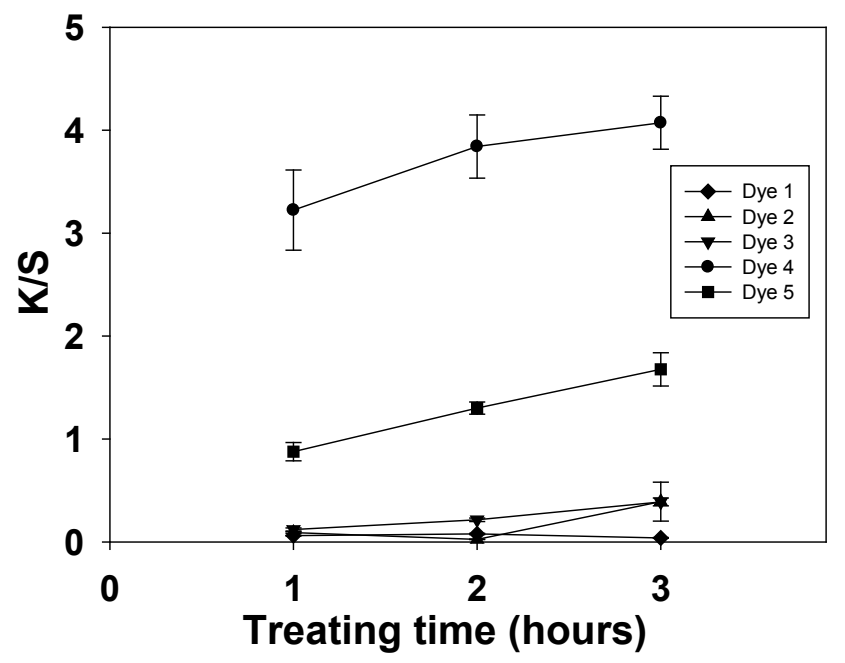

Figure 3. Effects of dye type on K/S of UHMWPE dyed with $2 \%$ omf in $\mathrm{ScCO}_{2}$

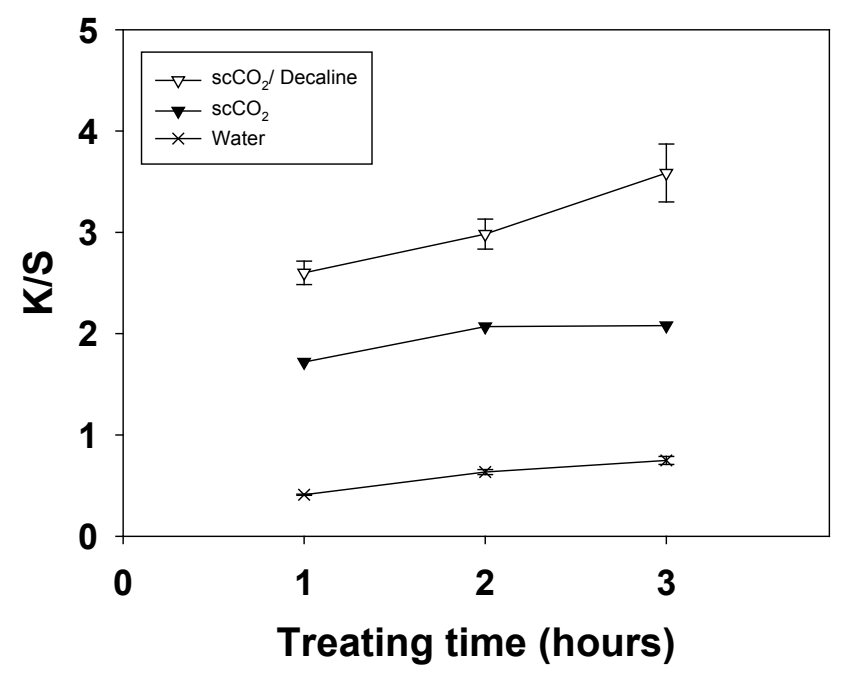

Figure 4. Effects of dyeing medium on K/S of UHMWPE dyed with $6 \%$ omf of Dye 4

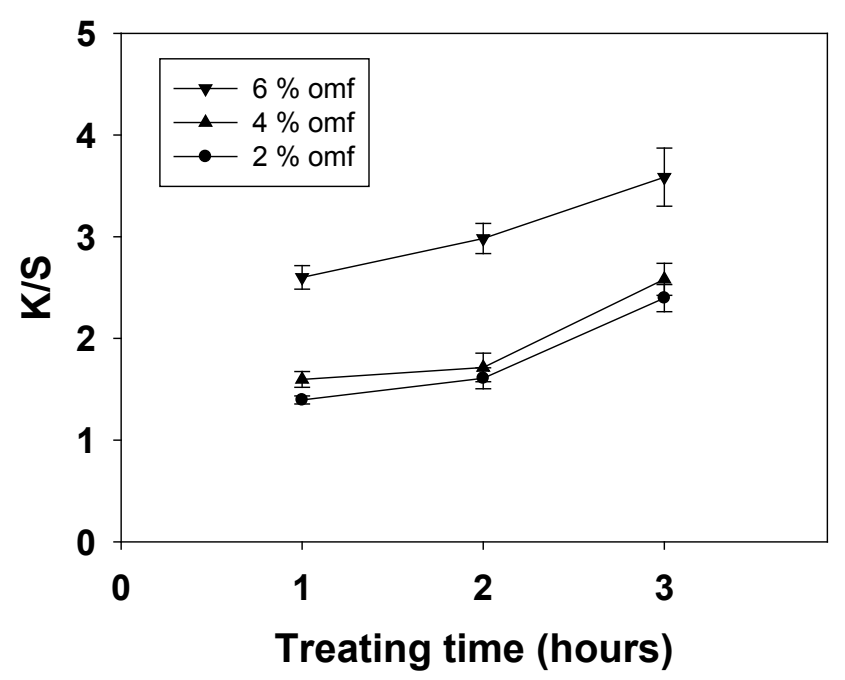

Figure 5. Effects of concentration of Dye 4 on $K / S$ of UHMWPE sample dyed in $\mathrm{ScCO}_{2}$ containing decaline 


\subsection{Dyeing conditions and physical properties}

The DC of UHMWPE was calculated from the heat of fusion estimated by DSC. The results are shown in Figure 6 . The DC of the virgin sample was approximately $90 \%[39,40]$. The water treatment and $\mathrm{scCO}_{2}$ treatment had no substantive effect on the $\mathrm{DC}$, although the $\mathrm{DC}$ remarkably decreased by dyeing in $\mathrm{scCO}_{2}$, especially on including decaline.

According to literature $[45,46]$, treatment of a polymer in $\mathrm{scCO}_{2}$ after including cosolvent promotes the crystallization through adsorption, swelling, plasticizing, and reorientation. However, adding dye and decaline in $\mathrm{scCO}_{2}$ reduced the crystallinity down to around $60 \%-70 \%$ in this study. It was assumed that the dye and decaline penetrate into the fiber in $\mathrm{scCO}_{2}$, which destroys the crystalline regions of UHMWPE; then, the dye and decaline remain in the UHMWPE due to either high affinity with UHMWPE or low affinity with $\mathrm{CO}_{2}$ after depressurization. This may disturb its reorientation, resulting in the decrease of the crystallinity in the $\mathrm{ScCO}_{2}$ process. Taking into account the result shown in Figure 5 , the increase of $K / S$ is strongly related to the reduction of crystallinity, which creates more amorphous adsorption sites for the dye.

Tensile test was performed to investigate the influence of treatment medium on the physical properties of UHMWPE fiber. The results are exhibited in Figure 7.

The maximal breaking strength of virgin UHMWPE fiber was $1.74 \mathrm{GPa}$, and it gradually decreased with the duration of the treatment, regardless of medium. Considering the decrease of DC shown in Figure 6, the reduction of breaking strength is verified by the lowering of crystallinity. On the other hand, the simple treatment with $\mathrm{scCO}_{2}$ also scaled down the strength, although it did not affect the crystallinity (Figure 6). This result may be attributed to the phenomenon of a crystal-to-crystal transformation in the UHMWPE, from an orthorhombic unit cell to a more mobile hexagonal phase in $\mathrm{scCO}_{2}$ [47]. It has been reported that the larger mobility of the hexagonal phases results in higher degree of freedom for rotations around the fiber axis. As a result, the $\mathrm{scCO}_{2}$ treatment decreases the breaking strength of UHMWPE fiber without decreasing the fibrous crystallinity.

The modulus of UHMWPE fiber was calculated and plotted against the DC in Figure 8.

The modulus of the virgin UHMWPE fiber was $53 \mathrm{GPa}$ and it was lowered by $\mathrm{scCO}_{2}$ treatment, which is directly related to the decrement in breaking strength. In addition, the modulus was enhanced with increase in the crystallinity, as compared with the samples treated in the same medium, as shown by the data points within the circles in Figure 8 . These results suggest that not only crystallinity but also other factors, e.g., crystal size, crystal structure, disorder of crystal, and orientation of molecules in the amorphous region, which are influenced by temperature, pressure, and solvent (i.e., medium of crystallization), determine the physical properties of UHMWPE. Further studies are required to explain the relations among those elements.

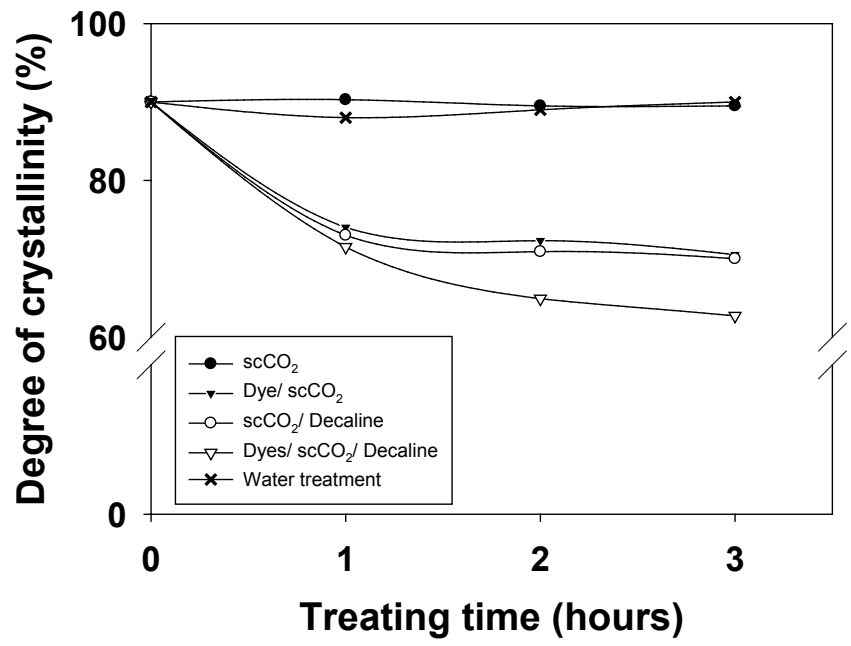

Figure 6. Effects of decaline on crystallinity of UHMWPE in $\mathrm{ScCO}_{2}$ dyeing with $6 \%$ omf of Dye 4

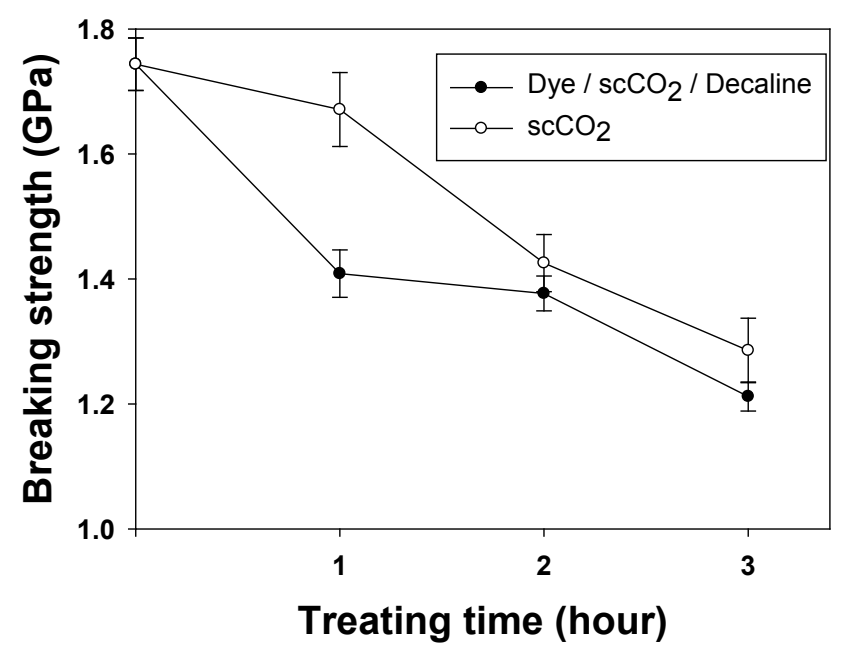

Figure 7. Effects of treatment medium on breaking strength of UHMWPE (the fabric was dyed with $6 \%$ omf of Dye 4 )

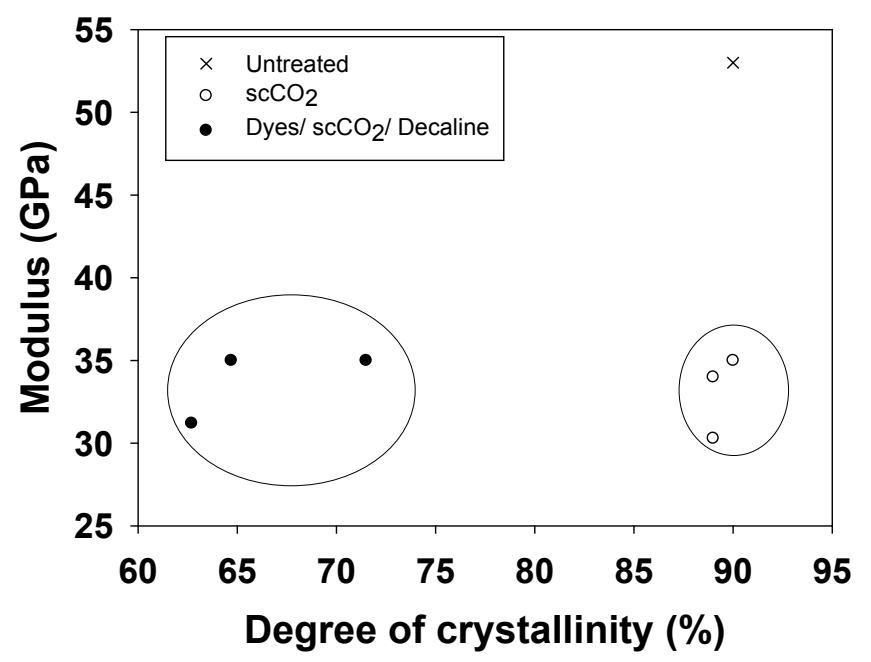

Figure 8. Effects of crystallinity on the modulus of UHMWPE (the fabric was dyed with $6 \%$ omf of Dye 4 ) 


\subsection{Color fastness}

The color fastness of UHMWPE fabric dyed in $\mathrm{scCO}_{2}$ to rubbing and sublimation is summarized in Table 1. Fastness of the fabric dyed for both 1 and 2 hours was excellent; however, the grade decreased to 3.0 for the 3-hour-dyed sample. This result is probably due to overdyeing, in which the dye molecules accumulate on the fiber surface. The accumulated dye was easily eliminated by rubbing and sublimation, resulting in the lower grade [48].

Table 1. Color fastness of UHMWPE fabric dyed with $6 \%$ omf of Dye 4 and decaline in $\mathrm{scCO}_{2}$

\begin{tabular}{|c|c|c|}
\hline \multirow{2}{*}{ Dyeing time (hours) } & \multicolumn{2}{|c|}{ Fastness (grade) } \\
\cline { 2 - 3 } & Rubbing & Sublimation \\
\hline 1 & $4-5$ & $4-5$ \\
\hline 2 & $4-5$ & $4-5$ \\
\hline 3 & 3 & 3 \\
\hline
\end{tabular}

\subsection{Antibacterial property}

In the test against $S$. aureus, B. cereus, and E. coli in AATCC Bacteriostasis Broth, the inoculated control and inoculated test fabrics were evaluated for percentage bacterial reduction by cell counting. The results of the percentage reduction test are shown in Table 2. The reduction percentages for $S$. aureus and $B$. cereus correspond to the bacterial numbers on the respective control tests, i.e., $(1.18,1.03,1.09) \times 10^{6} / \mathrm{mL}$. The reduction percentage was found to be $73 \%$ for $S$. aureus and $47.2 \%$ for $B$. cereus, while no activity was found against $E$. coli.

The UHMWPE fabric dyed with Dye 4 in $\mathrm{scCO}_{2}$ containing decaline showed certain good antibacterial activity due to the presence of the antipyrine moiety in the dye $[17,18]$, and the activity increased with increase in the dye concentration. However, the reduction of bacteria did not come close to $100 \%$.
This imperfect antimicrobial activity may be attributed to the low dye uptake, as expressed by the K/S values, i.e., a small amount of Dye 4 was adsorbed on the UHMWPE fiber surface, as compared with adsorption on the PET and Nylon 6 surfaces reported in previous studies $[17,18]$.

\section{Conclusions}

The UHMWPE fiber was dyed with five hydrozono propanenitrile dyes that have antimicrobial function in $\mathrm{ScCO}_{2}$. The dye uptake - expressed as the color strength, $K / S$ - was higher on the UHMWPE fabric dyed with relatively smaller molecule bearing double methyl groups, N'-(2-chloro-4-methylphenyl)-2-oxo-2-(ptolyl) acetohydrazonoyl cyanide (Dye 4), although the dyeability was significantly low, as compared with polyester and polyamide fibers. To improve the dyeability of UHMWPE fibers, decaline, which is generally used for gel spinning, was added in $\mathrm{scCO}_{2}$ as a cosolvent. The dye uptake - expressed as the color strength, K/S - increased by approximately $48 \%$ in comparison with a simple $\mathrm{scCO}_{2}$ dyeing for 1 hour, which was 5.2 times larger than the water-dyeing process. However, the process of UHMWPE in $\mathrm{scCO}_{2}$ containing decaline and/or dye adsorption to the fiber reduced its crystallinity and mechanical strength. The color strength increased with an increase in concentration of Dye 4 and treating time up to 3 hours, suggesting slow dye diffusion into UHMWPE fiber. The color fastness to rubbing and sublimation of UHMWPE dyed at lower concentration of Dye 4 was 4-5 grade, which is acceptable for commercial products. The UHMWPE fiber dyed with Dye 4 exhibited a good antibacterial property against Gram+ve bacteria (Staphylococcus aureus) and the activity was insufficient.

\section{Acknowledgments}

The authors wish to thank Toyobo Co., Ltd., which supplied the UHMWPE fiber. The rubbing test was gratuitously carried out at the Kyoto Municipal Institute of Industrial Technology and Culture, Kyoto, Japan.

Table 2. Antibacterial activity of UHMWPE dyed with Dye 4 and decaline in $\mathrm{scCO}_{2}$

\begin{tabular}{|c|c|c|c|c|}
\hline Microorganism & Concentration ( $\%$ omf) & $\begin{array}{l}\text { Control after incubation } \\
\text { period ( } 24 \text { hours) }\end{array}$ & Treated (cfu/mL) & $\begin{array}{c}\text { Bacterial } \\
\text { reduction (\%) }\end{array}$ \\
\hline \multirow{3}{*}{ Staphylococcus aureus } & 2 & \multirow{3}{*}{$\begin{array}{c}1.18 \cdot 10^{6} \\
3320 \times\left(37^{\top}\right)\end{array}$} & $\left(0.13^{\prime} 10^{6}\right)$ & 37.4 \\
\hline & 4 & & $\left(0.57^{\prime} 10^{6}\right)$ & 12.2 \\
\hline & 6 & & $\left(0.02^{\prime} 10^{6}\right)$ & 73.0 \\
\hline \multirow{3}{*}{ Bacillus cereus } & 2 & \multirow{3}{*}{$\begin{array}{c}1.03^{\prime} 10^{6} \\
3320 \times\left(90^{\top}\right)\end{array}$} & $\left(0.23^{\prime} 10^{6}\right)$ & 26.4 \\
\hline & 4 & & $\left(0.07^{\prime} 10^{6}\right)$ & 47.2 \\
\hline & 6 & & $\left(0.07^{\prime} 10^{6}\right)$ & 46.5 \\
\hline \multirow{3}{*}{ Escherichia coli } & 2 & \multirow{3}{*}{$\begin{array}{c}1.09 \cdot 106 \\
3320 \times\left(60^{\top}\right)\end{array}$} & $\left(1.09 \cdot 10^{6}\right)$ & \multirow{3}{*}{ No activity } \\
\hline & 4 & & $\left(2.65^{\prime} 10^{6}\right)$ & \\
\hline & 6 & & $\left(39.8^{\prime} 10^{6}\right)$ & \\
\hline
\end{tabular}




\section{References}

[1] Saus, W., Knitteel, D., Schollmeyer, E. (1993). Dyeing of textiles in supercritical carbon dioxide. Textile Research Journal, 63(3), 135-142.

[2] Knittel, D., Saus, W., Schollmeyer, E. (1993). Application of supercritical carbon dioxide in finishing processes. The Journal of The Textile Institute, 84(4), 534-552.

[3] Gebert, B., Saus, W., Knittel, D., Buschmann, H. J., Schollmeyer, E. (1994). Dyeing natural fibers with disperse dyes in supercritical carbon dioxide. Textile Research Journal, 64(7), 371-374.

[4] Abou Elmaaty, T., Abd El-Aziz, E. (2018). Supercritical carbon dioxide as a green media in textile dyeing: a review. Textile Research Journal, 88(10), 1184-1212.

[5] Perrut, M. (2000). Supercritical fluid applications: industrial developments and economic issues. Industrial and Engineering Chemistry Research, 39(12), 4531-4535.

[6] Haarhaus, U., Swidersky, P., Schneider, G. M. (1995). High-pressure investigations on the solubility of dispersion dyestuffs in supercritical gases by VIS/NIR-spectroscopy. Part I - 1,4-Bis-(octadecylamino)-9,10-anthraquinone and disperse orange in $\mathrm{CO} 2$ and N2O Up to $180 \mathrm{MPa}$. The Journal of Supercritical Fluids, 8(2), 100-106.

[7] Bhatti, I. A., Adeel, S., Parveen, S., Zuber, M. (2016). Dyeing of UV irradiated cotton and polyester fabrics with multifunctional reactive and disperse dyes. Journal of Saudi Chemical Society, 20(2), 178-184.

[8] Bhatti, I. A., Adeel, S., Siddique, S., Abbas, M. (2014). Effect of UV radiation on the dyeing of cotton fabric with reactive blue 13. Journal of Saudi Chemical Society, 18(5), 606-609.

[9] Adeel, S., Shahid, S., Khan, S. G., Rehman, F. U., Muneer, M., et al. (2018). Eco-friendly disperse dyeing of ultraviolettreated polyester fabric using disperse yellow 211. Polish Journal of Environmental Studies, 27(5), 1935-1939.

[10] Adeel, S., Khan S. G., Shahid, S., Saeed, M., Kiran, S., et al. (2018). Sustainable dyeing of microwave treated polyester fabric using disperse yellow 211 Dye. Journal of the Mexican Chemical Society, 62(1), 1-10.

[11] Cornelius, C., McCord, M., Bourham, M., Hauser, P. (2018). Desizing of PVA sized pet/cotton fabrics with atmospheric pressure plasma. Cellulose, 25(1), 869-881.

[12] Bach, E., Cleve, E., Schollmeyer, E. (2002). Past, present and future of supercritical fluid dyeing technology - an overview. Society of Dyers and Colourist, 32(1), 88-102.

[13] Banchero, M. (2012). Supercritical fluid dyeing of synthetic and natural textiles - a review. Society of Dyers and Colourist, 129(1), 2-17.

[14] Montero, G. A., Smith, C. B., Hendrix, W. A., Butcher, D. L. (2000). Supercritical fluid technology in textile processing: an overview. Industrial and Engineering Chemistry Research, 39(12), 4806-4812.

[15] Kim, T. K., Son, Y. A., Lim, Y. J. (2005). Affinity of disperse dyes on poly (ethylene terephthalate) in non-aqueous media: part 1: adsorption and solubility properties. Dyes and Pigment, 64(1), 73-78.

[16] Kim, T. K., Son, Y. A. (2005). Affinity of disperse dyes on poly (ethylene terephthalate) in non-aqueous media. Part 2: effect of substituents. Dyes and Pigment, 66(1), 19-25.
[17] Özcan, A. S., Özcan, A. (2005). Adsorption behavior of a disperse dye on polyester in supercritical carbon dioxide. The Journal of Supercritical Fluids 35(2), 133-139.

[18] Banchero, M., Ferri, A., Manna, L. (2009). The phase partition of disperse dyes in the dyeing of polyethylene terephthalate with a supercritical CO2/methanol mixture. The Journal of Supercritical Fluids, 48(1), 72-78.

[19] Banchero, M., Ferri, A., Manna, L., Sicardi, S. (2006). Dye uptake and partition ratio of disperse dyes between a PET yarn and supercritical carbon dioxide. The Journal of Supercritical Fluids, 37(1), 107-114.

[20] Liao, S. K., Ho, Y. C., Chang, P. S. (2000). Dyeing of nylon 66 with a disperse-reactive dye using supercritical carbon dioxide as the transport medium. Society of Dyers and Colourist, 116(12), 403-407.

[21] Liao, S. K. (2004). Dyeing nylon-6, 6 with some hydrophobic reactive dyes by supercritical processing. Journal of Polymer Research, 11(4), 285-291.

[22] Abou Elmaaty, T., Ma, J., El-Taweel, F., Abd El-Aziz, E., Okubayashi, S. (2014). Facile bifunctional dyeing of polyester under supercritical carbon dioxide medium with new antibacterial hydrazono propanenitrile dyes. Industrial and Engineering Chemistry Research, 53(40), 1556615570.

[23] Abou Elmaaty, T., Abd El-Aziz, E., Ma, J., El-Taweel, F., Okubayashi, S. (2015). Eco-Friendly disperse dyeing and functional finishing of nylon 6 using supercritical carbon dioxide. Fibers, 3(3), 309-322.

[24] Liao, S. K., Chang, P. S., Lin, Y. C. (2000). Analysis on the dyeing of polypropylene fibers in supercritical carbon dioxide. Journal of Polymer Research, 7(3), 155-159.

[25] Junrong, Y., Zuming, H., Zhaofeng, L. (2006). Study on the modification of ultrahigh molecular weight polyethylene fiber with polar polymers. Research Journal of Textile and Apparel, 10(1), 1-7.

[26] Berger, L., Kausch, H. H., Plummer, C. J. G. (2003). Structure and deformation mechanisms in UHMWPEfibres. Polymer, 44(19), 5877-5884.

[27] Kim, T., Jeon, S., Kwak, D., Chae, Y. (2012). Coloration of ultra high molecular weight polyethylene fibers using alkylsubstituted anthraquinoid blue dyes. Fibers and Polymers, 13(2), 212-216.

[28] Kim, T., Jeon, S. (2013). Coloration of ultra high molecular weight polyethylene fibers using alkyl-substituted monoazo yellow and red dyes. Fibers and Polymers, 14(1), 105-109.

[29] Ichiro, E., Yosuke, K., Hisaaki, K., Shin, S. (2011). Graft polymerization using radiation-induced peroxides and application to textile dyeing. Radiation Physics and Chemistry, 80(2), 169-174.

[30] Barham, P. J., Keller, A. (1985). High-strength polyethylene fibers from solution and gel spinning. Journal of Materials Science, 20(7), 2281-2302.

[31] Smith, P., Lemstra, P. J., Pijpers, J. P. L., Kiel, A. M. (1981). Ultra-drawing of high molecular weight polyethylene cast from solution. Colloid and Polymer Science, 259(11), 1070-1080.

[32] Thein, K., Kenichi, F., Myung, H. C., Takechi, K. (1989). Melting and crystallization of gelation crystallized ultrahigh molecular weight polyethylene. Macromolecules, 22(5), 2238-2244. 
[33] Andrew, J. B., Jianxin, Z., Clive, J. R., Edward, L., Steven, M. H. (2005). Novel nanostructured polymeric composites of polycaprolactone and ultra-high-molecular-weight polyethylene via a supercritical-fluid route. Advanced Materials, 17(3), 364-367.

[34] Abou Elmaaty, T., El-Taweel, F., Abd El-Aziz, E., Yusif, M., Okubayashi, S. (2014). Facile bifunctional dyeing of polyester fabrics with new antibacterial $\beta$-oxoalkanenitriles disperse dyes. International Journal of Scientific and Engineering Research, 5(4), 703-706.

[35] DSC Measurement of Polyethylene. 04 24, 2018. Web site: https://www.hitachi-hightech.com/file/global/pdf/products/ science/appli/ana/thermal/application_TA_026e.pdf.

[36] Ma, J., Okubayashi, S. (2015). Dyeablility of ultra high molecular weigh polyethylene fiber using scCO2. Proceedings of the 68th Annual Meeting, The Textile Machinery Society of Japan. 108-109.

[37] Ma, J., Okubayashi, S. (2017). Improvement in dyeability of UHMWPE fiber using supercritical CO2. Proceedings of Asia and Africa Science Platform Program. 109-110.

[38] Ma, J., Okubayashi, S. (2017). Improvement in dyeability of UHMWPE fiber using Supercritical CO2. Proceedings of the 54th Senshoku Kagaku Touronkai. 17-18.

[39] Ma, J., Okubayashi, S. (2016). Effects of co-solvent on dyeability of ultra-high molecular weight polyethylene fiber in supercritical CO2. Proceedings of International Symposium on Advances in Sustainable Polymers. 186188.

[40] Ma, J., Okubayashi S. (2016). Effects of Co-solvent on Dyeablility of Ultra High Molecular Weigh Polyethylene fiber in Supercritical CO2. Proceedings of the 69th Annual Meeting, The Textile Machinery Society of Japan. 40-41.

[41] Aiqin, H., Bo, C., Jinjin, D., Kai, Z. (2010). Using supercritical carbon dioxide as solvent to replace water in polyethylene terephthalate (PET) fabric dyeing procedures. Journal of Cleaner Production, 18(10-11), 1009-1014.
[42] Chien, T. W., Wen, F. L. (2001). Scouring and dyeing of polyester fibers in supercritical carbon dioxide. Journal of Chemical Engineering of Japan, 34(2), 244-248.

[43] Laijiu, Z., Huanda, Z., Bing, D., Ju, W., Shibui, G., et al. (2015). Dyeing procedures of polyester fiber in supercritical carbon dioxide using a special dyeing frame. Journal of Engineered Fibers and Fabrics, 10(4), 35-46.

[44] Lucio, C. F., Helen, R. M., Jose, C. S., Jurgen, A., Andresa, C. F., et al. (2014). Dyeing of polyethylene terephthalate fibers with a disperse dye in supercritical carbon dioxide. Textile Research Journal, 84(12), 1279-1287.

[45] Hirogaki, K., Zhao, X., Tabata, I., Hisada, K., Okubayashi, S., et al. (2006). Structural changes in poly(ethylene terephthalate) induced by supercritical carbon dioxide containing a cosolvent as a modifier. The Society of Fiber Science and Technology, Japan, 62(8), 180-185.

[46] Sobieraj, M. C., Rimnac, C. M. (2009). Ultra high molecular weight polyethylene: mechanics, morphology, and clinical behavior. Journal of Mechanical Behavior of Biomedical Materials, 2(5), 433-443.

[47] Manuel, G. L., John, S., Alan, J. L. (2003). Drawing of ultrahigh molecular weight polyethylene fibers in the presence of supercritical carbon dioxide. Journal of Polymer Science. Part B: Polymer Physics, 41(12), 13751383.

[48] Miyazaki, K., Tabata, I., Hori, T. (2011). Effects of molecular structure on dyeing performance and colour fastness of yellow dyestuffs applied to polypropylene fibres in supercritical carbon dioxide. Society of Dyers and Colourists. Coloration Technology, 128(1), 51-59. 